\title{
Molecular Characterization of Citrobacter freundii Isolated from Neonates in Neonatal Intensive Care Unit of Nepal
}

\author{
Thapa B', Tribuddharat $C^{2}$ \\ 'Dr. Badri Thapa, MBBS. Ph D, Lecturer, Kathmandu Medical College, Genesis Laboratory and Research Centre, \\ Communicable Disease Poly Clinic and Research Centre, Kathmandu, Nepal, ${ }^{2}$ Dr. Chanwit Tribuddharat, MD, Ph D, \\ Assistant Professor, Department of Microbiology, Faculty of Medicine, Siriraj Hospital, Mahidol University, Bangkok, \\ Thailand.
}

Address for correspondence: Dr. Badri Thapa, E-mail: badri_bishal@yahoo.com

\begin{abstract}
Introduction: Nosocomial Citrobacter spp. is emerging as a successful nosocomial pathogen in neonates in Nepal. The important risk factor being poor infection prevention and control practices. The objective of this study was to investigate the clonal relatedness of Citrobacter freundii isolated from clinical and nonclinical sources in Neonatal Intensive Care Unit (NICU) and to determine the presence of Extended Spectrum Beta-Lactamase (ESBL) genes and class 1 integron element. Materials and Methods: Polymerase chain Reaction (PCR) and PCR-Randomly Amplified Polymorphic DNA typing of the isolates were performed in three isolates to amplify class 1 integron element integrase gene, ESBL genes, and to study the clonal relatedness, respectively. Results: Two isolates harbored class 1 integron element. The $b a_{\text {CTX-M }}$ was present in all isolates and $b / a_{\text {TEM-1 }}$ was present in one isolate. An isolate carried bla $a_{\text {TTXM }}$ and $b l a_{\text {TEM-1 }}$ genes. All of these isolates were not clonally related. Conclusion: The study for the first time documented the emergence and spread of ESBL genes and class 1 integron element in multidrug resistant $C$. freundii in Nepal and urge for monitoring and surveillance of these strains.
\end{abstract}

Key words: Citrobacter spp., ESBL, PCR-RAPD, class 1 integron element

\section{Introduction}

A mong nosocomial pathogens causing nosocomial infections, Staphylococcus aureus, coagulase negative Staphylococcus spp., Acinetobacter spp., Pseudomonas spp., Escherichia coli, Kleibsella spp., Enterobacter spp., and Citrobacter spp. are most common'. Citrobacter nosocomial infection in neonates is a cause of substantial rise in morbidity and mortality of neonates in the hospital in Nepal and globally ${ }^{1,2,3,4}$. The poor infection prevention and control practices have been a major determining factor for the spread of this nosocomial pathogen'. The infection in neonates is either horizontally transferred as a nosocomial infection or vertically transferred from mother during delivery ${ }^{5}$. The imprudent and less potent use of antibiotics has also led to the emergence of the multidrug resistant nosocomial pathogens ${ }^{6}$. Numerous studies have already

Manuscript received: $6^{\text {th }}$ February 2012.

Reviewed: $31^{\text {st }}$ March 2012

Author Corrected: $2^{\text {nd }}$ April 2012

Accepted for Publication: $30^{\text {th }}$ April 2012 shown Citrobacter carrying Extended Spectrum BetaLactamase genes $\left(b / a_{\mathrm{CTX}-\mathrm{M}^{\prime}} b / a_{\mathrm{TEM}-1^{\prime}}\right.$ and $\left.b / a_{\mathrm{SHV}}\right)$ and a carriage of class 1 integron element ${ }^{7}$.

Citrobacter spp. is commonly infecting adult patients admitted to the hospitals in $\mathrm{Nepal}^{8,9}$. Infections like, respiratory tract, urinary tract, intra-peritoneal, wound, sepsis, meningitis, and brain abscess are common to this pathogen ${ }^{5}$. Neonates and infants are also at risk of developing Citrobacter osteomyelitis, septic arthritis, lung abscess, skin infection and urinary tract infection ${ }^{10,11,12,13}$. Among Citrobacter spp., Citrobacter freundii is the commonest species that has been described as a nosocomial pathogen ${ }^{14}$. However, this pathogen infecting neonates was never described in Nepal. We have recently described the isolation of Citrobacter spp. from various clinical and non-clinical specimens originated from the neonates admitted in Neonatal Intensive Care Unit (NICU) ${ }^{2}$. In light with this fact, here we compared the genotypes of $C$. freundii isolated from the clinical and non-clinical sources and 
determined the possession of class 1 integron element and $\mathrm{ESBL}$ genes in these isolates.

\section{Material and Methods}

The study had isolated 12 multidrug resistant Citrobacter spp. from various clinical and non-clinical sources. They were grouped into five antibiotypes (I to $\mathrm{V})$. The isolate $\mathrm{C} 109$, isolated from the nasal prong and C316709 were grouped with four other isolates in antibiotype I. These isolates along with C3409 belonging to antibiotype $V$ were selected for the present study. The identification of $C$. freundii was carried out as described previously ${ }^{15}$. Hydrogen sulfide production on Triple Sugar Iron Agar slant along with other biochemical tests was used to confirm as $C$. freundii. Overnight grown bacterial colonies were emulsified in $1 \mathrm{ml}$ sterile distilled water and boiled for 1 minute. The emulsified colonies were centrifuged at $13,000 \mathrm{~g}$ for 5 minutes and supernatant was used for colony Polymerase Chain Reaction (PCR). PCR-Randomly Amplified Polymorphic DNA (PCRRAPD) was performed as described earlier using $1 \mu$ of supernatant as a DNA template ${ }^{16}$. The class 1 integron element integrase gene (int/1) and ESBL genes (bla $a_{\text {CTX-M' }}$ $b / a_{\mathrm{TEM}-1}$, and $\left.b / a_{\mathrm{SHV}}\right)$ were amplified using the protocol published ${ }^{17}$. Briefly, the reaction mixture contained $0.5 \mathrm{M}$ each primer, $250 \mathrm{M}$ each deoxynucleoside triphosphate, $1 \mathrm{U}$ Taq DNA polymerase (Finzymes), $2.5 \mu \mathrm{l}$ of $10 \mathrm{X}$ PCR buffer, and 100-500 ng of total genomic DNA in a final volume of $25 \mu \mathrm{l}$. Amplification was performed in a Perkin-Elmer thermocycler 2400 model for $5 \mathrm{~min}$ at $95^{\circ} \mathrm{C}$, followed by 30 consecutive cycles of $1 \mathrm{~min}$ at $95^{\circ} \mathrm{C}, 1 \mathrm{~min}$ at $50^{\circ} \mathrm{C}$ for $b / a_{\mathrm{TEM}}$ gene, $55^{\circ} \mathrm{C}$ for $b / a_{\mathrm{SHV}}, 58^{\circ} \mathrm{C}$ for $b / a_{\mathrm{CTX}-\mathrm{M}}$ gene, and $1 \mathrm{~min}$ at $72^{\circ} \mathrm{C}$, with a single final extension step of $10 \mathrm{~min}$ at $72^{\circ} \mathrm{C}$. PCR products were separated by electrophoresis in a 1.5 percent agarose gel and stained with ethidium bromide.

\section{Results}

The isolate C316709 and C109 were sensitive to ofloxacin, ciprofloxacin and norfloxacin while isolate C3409 was resistant to all eleven antibiotics tested (Table 1). The Int/1 was amplified from two isolates (C3409 and C109). All isolates were positive for bla $a_{\text {CTX-M }}$ and an isolate
C3409 also harbored $b / a_{\mathrm{TEM}-1} \cdot b / a_{\mathrm{SHV}}$ was not amplified from all isolates. The PCR-RAPD genotyping of these isolates showed three different genotypes ( $a, b$ and $c$ ) and they were not clonally related (Table 1 and Fig. 1).

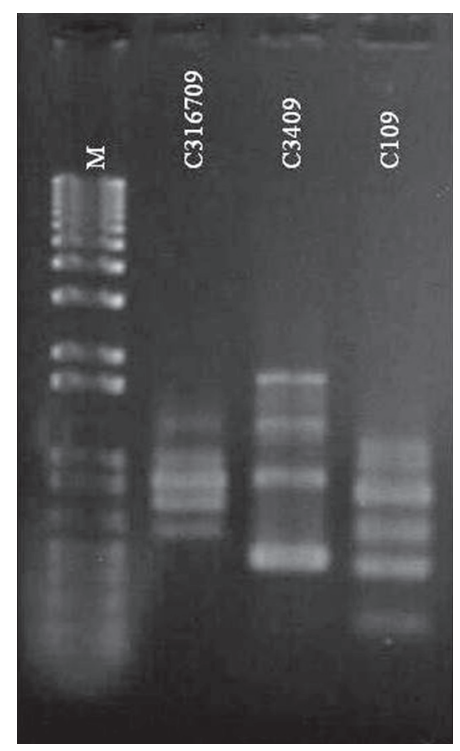

Fig1: PCR-RAPD patterns of $\boldsymbol{C}$. freundii isolates. The lanes have been marked with the respective isolates. $M$, Molecular weight marker (1 $\mathrm{Kb}+$ Invitrogen, USA). Lane 1, pattern a; lane 2, pattern b and lane 3, pattern c. The PCR-RAPD was performed in Department of Microbiology, Siriraj Hospital, Bangkok, Thailand.

\section{Discussion}

In this study, the $C$. frundii isolated from nate and innate sources from Neonatal intensive Care Unit (NICU) were characterized. Isolates C316709 and C109 had similar antibiotype, but were not clonally related by PCR-RAPD typing. The typing also revealed that the $C$. freuidii isolated from clinical and non-clinical sources were not related highlighting for other sources that could not be traced. PCR-RAPD is an arbitrarily primed $P C R$ and is more discriminatory. Less discriminatory and more robust molecular typing tools like, ribotyping and multi-locus sequence typing (MLST) are necessary for clonal analysis ${ }^{18}$. We could not include all isolates for genotyping and the relatedness of those isolates to these clones ( $a, b$, and c) could not be ascertained.

Table 1: Characteristics of Citrobacter freundii isolates

\begin{tabular}{|c|c|c|c|c|c|c|c|}
\hline & & & \multicolumn{3}{|c|}{ ESBL genes } & \multirow[b]{2}{*}{ intl1 } & \multirow[b]{2}{*}{ PCR-RAPD } \\
\hline ID & Source & AST (sensitive to) & $b l a_{\text {TEM-1 }}$ & $b l a_{\mathrm{SHV}}$ & $b l a_{\text {CTX-M }}$ & & \\
\hline C316709 & US & CF, OF, NX & - & - & + & - & $A$ \\
\hline C3409 & US & None & + & - & + & + & $B$ \\
\hline C109 & NP & OF, CF, NX & - & - & + & + & C \\
\hline \multicolumn{8}{|c|}{$\begin{array}{l}\text { US, Umbilicab Swab; NP, Nasal Prong; Antibiotics tested ( } \mu \mathrm{g} / \text { disc): Ampicillin (10), Piperacillin (100), Amoxy-Clav } \\
\text { (20/10), Ceftriaxone (CI) (30), Cephalexin (30), Amikacin (30), Netilmicin (30), Ciprofloxacin (CF) (5), Ofloxxacin (OF) (5) } \\
\text { Norfloxacin (NX) (10), Sulphamethoxazole+Trimithorprim (23.75+1.25). }\end{array}$} \\
\hline
\end{tabular}


Despite the fact that Citrobacter spp. infection is prevalent in Nepal, it is unfortunate that no systematic molecular studies have been conducted, however the isolation of Citrobacter spp. have been described ${ }^{2,8,9}$. In this study, we have shown the emergence of $C$. freundii carrying class 1 integron element and bla $a_{\text {CTX-M }}$ and bla $a_{\text {TEM- }}$ ESBL genes for the first time in Nepal. The present study has also identified $C$. freundii strain simultaneously harboring bla $a_{\text {CTX-M }}$ and $b / a_{\text {TEM-1 }}$ which has also been described in India ${ }^{18}$. These Indian isolates also carried $b / a_{\mathrm{SHV}}$ and $b / a_{\mathrm{ampC}}$ along with $b / a_{\mathrm{CTX}-\mathrm{M}}$ and $b / a_{\mathrm{TEM}-1}$. C. freundii carrying bla $a_{\text {СTX-M }}$ has also been described elsewhere ${ }^{7}$. Enterobacteriaceae carrying class 1 integron element have been described, however the reports describing the presence of this mobile genetic element in Citrobacter is scarce. We have also identified $C$. freundii carrying this mobile genetic element. Most of the ESBLs are carried in this mobile genetic element ${ }^{19}$ and the carriage of ESBL genes in this element was not investigated. Citrobacter spp. infection has frequently been increasing as a cause of serious concern, especially for neonates and immunocompromised adults. The increasing antibiotic resistance is also noteworthy for $C$. freundii.

The neonatal mortality of Nepal was 33/1000 live births in 2006 and the preliminary findings of National Demographic and Health Survey 2011 has shown no difference in $\mathrm{NMR}^{20}$. To address maternal health, Ministry of Health and Population, Government of Nepal has started "AMMA" program, which aims to motivate institutional delivery to decrease maternal mortality. In light of emergence of class 1 integron element and ESBL harboring $C$. freundii, government's effort of advocating institutional delivery and saving maternal lives will position neonates at increased risk of neonatal morbidity and mortality if infection prevention and control policies and practices are not in place. Furthermore the spread of mobile genetic element and resistance genes will help in emergence of multidrug resistant pathogens and might pose challenge for saving newborns.

In conclusion, this study has highlighted the spread of oligoclonal population of $C$. freundii neonatal nosocomial infection in NICU, Nepal and has also documented the spread of bla $a_{\text {CTX-M }}$ and $b / a_{\text {TEM-1 }}$ and class 1 integron element carrying $C$. freundii in Nepal.

Acknowledgements: Authors would like to acknowledge Asst. Prof. Dr. Chanwit Tribuddharat for allowing the authors to conduct the experiment at his laboratory located at Department of Microbiology, Siriraj Hospital, Bangkok, Thailand.

Funding: None

Conflict of interest: None to declare.

Permission from IRB: Yes

\section{References}

1. Kamath S, Mallaya S, Shenoy S. Nosocomial infections in neonatal intensive care units: profile, risk factor assessment and antibiogram. Indian J Peadiatr 2010;77:37-9.

2. Khadka SB, Thapa B, Mahat K. Nosocomial Citrobacter Infection in Neonatal Intensive Care Unit in a Hospital of Nepal. J Nepal Paediatr Soc 2011;31:105-09.

3. Saraswathi KDA, Gogate A, Fernande AB. Citrobacter sepsis in infants. Indian Peadiatr 1995;31:359-62.

4. Shrestha P, Das BK, Bhatta NK, Jha DK, Das B, Setia $A$ et al. Clinical and Bacteriological profiles of blood culture positive sepsis in newborns. J Nepal Paediatr Soc 2008;27:64-7.

5. Mohanty S, Singhal R, Sood S, Dhawan B, Kapil A, Das BK. Citrobacter infections in a tertiary care hospital in Northern India. J Infect 2007;54:58-64.

6. Thapa B, Mahat K. In-vitro activity of antibiotics and brands of ceftriaxone against clinical isolates. $J$ Nepal Med Assoc 2010;49:225-7.

7. Kim J, Lim YM. Prevalence of derepressed AmpC mutants and extended-spectrum beta-lactamase producers among clinical isolates of Citrobacter freundii, Enterobacter spp., and Serratia marcescens in Korea: dissemination of CTX-M-3, TEM-52, and SHV-12. J. Clin Microbiol 2005;43:2452-5.

8. Banjara MR, Sharma AP, Hoshi AB, Tuladhar NR, Ghimire $P$, Bhatta DR. Surgical wound infections in patients of Tribhuvan University Teaching Hospital. Nepal Health Res Counc 2003;3:41-5.

9. Thapa B, Adhikari P, Mahat K, Chettri M, Joshi LN. Multidrug-resistant nosocomial Citrobacter in a hospital in Kathmandu. J Nepal Med Coll 2009;11:195-9.

10. Jansen RD, Meadow WL, Schwartz IK, Ogata ES. "Bacteriological bit", Citrobacter diversus osteomyelitis in a neonate. Clin Pediatr (Phila) Bacteriol 1981;20:791.

11. Bruehl CL, Listernick R. Citrobacter freundii septic arthritis. J Paediatr Child Healt 1992;28:402-3.

12. Shamir R, Horev G, Merlob P, Nutman J. Citrobacter diversus lung abscess in a preterm infant. Pediatr Infect Dis J 1990;9:221-2.

13. Barton LL, Walentik C. Citrobacter diversus urinary tract infection. Am J Dis Child 1982;136:467-8. 
14. Samonis G, Karageorgopoulos DE, Kofteridis DP, Matthaiou DK, Sidiropoulou V, Maraki S et al. Citrobacter infections in a general hospital: characteristics and outcomes. Eur J Infect Dis 2009;28:61-8.

15. Ng SY, Kwang L, Tan TY. Identification of Gramnegative bacilli directly from positive blood culture vials. J Med Microbiol 2007;56:475-9.

16. Thapa B, Tribuddharat C, Srifuengfung S, Dhiraputra C. High prevalence of bla $a_{\mathrm{OXA}-23}$ in oligoclonal carbapenem-resistant Acinetobacter baumannil in Siriraj Hospital, Mahidol University, Bangkok, Thailand. Southeast Asian J Trop Med Public Health 2010;41:625-35.

17. Tribuddharat C, Srifuengfung S, Chiangjong W. A Correlation between phenotypes and genotypes of extended-Spectrum beta-Lactamase (ESBL)- producing Klebsiella pneumoniae in a University Hospital, Thailand. Dis Antimicrob Agents 2007;24:117-23.

18. Norskov-Lauritsen N, Sandvang D, Hedegaard J, Fussing V, Mortensens KK, Sperling-petersen HU, et al. Clonal origin of aminoglycoside-resistant Citrobacter freundii isolates in Danish county. J Med Microbiol 2001;50:636-41.

19. Shahid, M. Citrobacterspp. simultaneously harboring bla $a_{\mathrm{CTX}-\mathrm{M}^{\prime}}$ bla $a_{\mathrm{TEM}}$ bla $a_{\mathrm{SHV}^{\prime}}$ bla $a_{\mathrm{ampC}}$ and insertion sequences IS26 and orf513: an evolutionary phenomenon of recent concern for antibiotic resistance. J Clin Microbiol 2010;48:1833-38.

20. Ministry of Health and Population. Government of Nepal. Nepal Demographic and Health Survey, 2011. Nepal.

\section{How to cite this article?}

Thapa B, Tribuddharat C. Molecular Characterization of Citrobacter freundii Isolated from Neonates in Neonatal Intensive Care Unit of Nepal. J Nepal Paediatr Soc 2012;32(2):132-135. 